\title{
Supportive Expressive Therapy for Generalized Anxiety Disorder in Client with Burst Fractures Frankle - C
}

Kiki Ramiza*

Professional Psychology, Islamic University of Indonesia, Yogyakarta, Indonesia

*Corresponding author: 17915045@students.uii.ac.id

Article history: Received: 11 January 2020 Received in revised form: 28 June 2020 Accepted: 10 May 2021 Published online: 09 August 2021

\begin{abstract}
This article presents a case study of a client with burst fracture frankle-C. This client also has generalized anxiety disorder. Supportive expressive therapy was used as therapeutic intervention. A burst fracture is a type of traumatic spinal injury in which a vertebra breaks from a high-energy axial load. The psychological problems often experienced by persons with body disabilities, such as burst fracture francle-C. This is a quantitative research with a single client. While collecting the data, used interview methods (autoanamnesa and alloanamnesa), observation, and psychological tests (DAP, BAUM, BAI, and Sack's Sentence Completion Test). The result before the practitioner gives the Beck Anxiety Inventory, the client's anxiety is 20 (moderate anxiety), after intervention 15 (mild anxiety), and follow up 11 (mild anxiety). In addition, the client is also better able to understand his condition and the problems being faced. The catharsis process that has happened so far makes the client able to express what he feels and thinks so as to make the client feel the perceived burden is reduced. Clients can begin to open up to family members at home and conduct simple chats when parents are at home to reduce the habit of repression that was previously done. The technique and also the process of the therapeutic process along the therapy session will be discussed in detail.
\end{abstract}

Keywords: Supportive Expressive Therapy, Client, Burst Fracture Frankle-C, Generalized Anxiety Disorder, Traumatic Spinal Injury

(C) 2021 Penerbit UTM Press. All rights reserved

\subsection{INTRODUCTION}

Generalized Anxiety Disorder (GAD) is a relatively common disorder associated with high rates of chronicity and moderate dysfunction. A survey conducted on 150,000 adults in 26 countries, the DSM-5 (Diagnostic and Statistical Manual of Mental Disorders) general anxiety disorder had a combined lifetime prevalence of $3.7 \%$, a prevalence of 12 months of $1.8 \%$, and 30 days. prevalence $0.8 \%$. this disorder is significantly more common and disturbing in developed countries than developing countries (Ruscio, Hallion, \& Lim, 2017).

The results showed that about one third of clients with GAD had an onset of adolescence or early twenties and a mean length of illness of 6-10 years, and then unlike other anxiety disorders, the course of GAD is characterized by a relatively early onset of a high degree of chronicity (Beesdo, Knappe, \& Pine, 2009). This is a case of generalized anxiety disorder in a Client with a c-frankle burst fracture. The New York Institute of Neurology defines burst $=$ forced fracture, fracture $=$ fracture. A fracture is an injury in which the spine, the main bone of the spine, breaks in different directions.

Burst fractures occur due to failure under the axial load of both anterior and middle columns originating from one or both ends of the plates of the same vertebra (Denis, 1983). Cervical injury is a pelvic bone injury that most often causes disability and death, from several studies there is a correlation between the level of cervical injury with morbidity and mortality, namely the higher the cervical injury rates the higher the morbidity and mortality (Stewart, 2002).

About $10 \%$ of patients with decreased consciousness who are sent to the emergency room due to traffic accidents always experience cervical injuries, both cervical spine injuries, supporting tissues, and cervical spine injuries (Hackl, Hausberger, Sailer, Ulmer and Gassner, 2001). Traffic accidents and falls are the cause of most cervical fractures. Traumatic cervical subaxis (C3-7) is more common than cervical C1 and C2 (Hackl et al., 2001). Cervical trauma often occurs in patients with a history of motor vehicle accidents with high speed, trauma to the face and head, neurological deficits, neck pain, and multiple trauma (Weishaupt, 2010).

The psychotherapy approach described within this chapter represents an application of Luborsky (1984) Supportive-Expressive (SE) dynamic therapy manual to generalized anxiety disorder (GAD). The treatment is brief (4 sessions) and focal in nature. While a diagnosis of GAD does not lead to a radically different treatment approach than standard brief SE, there are important treatment issues and emphases that are relevant to GAD Clients, requiring this addendum to the generic SE manual. The specific elements of SE treatment as delivered to GAD Clients become even more important in a research context where the mission is to standardize treatment so that studies can be replicated and efficacious treatments disseminated (Christoph, Christoph, Palacio, Fichter, \& Rudick, 2015).

Thus, on the one hand we are not trying to present a "new" dynamic therapy, but on the other hand we are trying to provide a further level of specificity of SE treatment for GAD clients which we hypothesize will give a better outcome. Researchers believe a combination 
of a general manual plus more specific guidance on applying SE to GAD can achieve this goal (Christoph, Christoph, Palacio, Fichter, \& Rudick, 2015).

\title{
2.0 LITERATURE REVIEW
}

\author{
Supportive Expressive Therapy
}

Supportive therapy has been used in the literature in two different ways. Supportive therapy is characterized as a recommended method of therapy for patients who are willing to be instructed, confident, and supported by the dominant person. Patients are unsuitable for intensive therapy which is almost universally accepted as appropriate treatment (Beres, 1956). Recently, there are many known psychoanalyticoriented therapy, psychodynamic psychotherapy, exploratory therapy, and expressive therapy, which are the terms that researchers will use. The patient-therapist relationship is a real one, and is usually not analyzed. Defenses are generally supported by them maladaptive. Acquisition of insight into a significant success goal. Every effort is made to measure and assess and change therapy, although it is not always possible to avoid all discomfort (Amodeo, 1995).

Supportive therapy uses direct measures to ameliorate symptoms and to maintain, restore, or improve self-esteem, ego function, and adaptive skills. Self-esteem involves the patient's sense of efficacy, confidence, hope, self-regard. Ego functions include relation to reality, thinking, defense formation, regulation of affect, synthetic function, and others as enumerated by Beres (Bellak, 1958). In practice, psychotherapy for most patients is a blend of supportive-expressive and expressive-supportive components (Luborsky, 1984). Only when psychotherapy is an adjunct to medical treatment or psychophannacologic management is it likely to be limited to the core supportive concerns of self-esteem, ego function, and adaptive skills, without efforts to understand relationships or patterns of be ha vi or and thinking. With the most severely impaired patients, disturbances in ego functions must be addressed. With healthier patients, ego function is of less concern; the emphasis is then on adaptive skills. (Dewald, 1971). The content of therapeutic sessions is likely to involve attention to relationships, attitudes, and feelings and often focuses on discovering how patterns that made sense at some time in the past are perpetuated when they no longer serve an adaptive purpose. This is the expressive component. With healthier patients treatment becomes expressive-supportive. Supportive techniques are used less often, and then primarily to enhance self-esteem. But, even though there is less use of specific supportive techniques with healthier patients, treatment that follows the supportive model maintains the technical differences that characterize the supportive and expressive poles of the spectrum. The therapist always has self-esteem in mind, adds words of praise whenever appropriate, and, unless there is specific reason to do otherwise, employs measures to minimize anxiety and frustration (Frank and Frank, 1991).

\section{Burst Fracture Frankle-C}

Burst fractures of the fifth lumbar vertebra are rare, and there have been few reports in this client, which are characterized by their unique anatomical and biomechanical features. This retrospective analysis reported ten patients whose L5 fractures were stabilized with a short internal fixator combined with posterior fusion and transpedicular bone grafts. The mean follow-up period was 22 months. Radiometric were surveyed and compared with functional results. The height of the fractured spine is almost unchanged throughout the course. Loss of lordosis of $4^{\circ}$ in the upper disc space and $4^{\circ}$ in the lower disc space was observed after surgery (Kaminski, Muller and Muhr, 2002).

At the time of follow-up, the values of segmental lumbar lordosis were significantly below the preoperative level. The narrowing of the neural canal was reduced from $57 \%$ to $28 \%$ with the surgical intervention. However, there was no correlation between the functional and the radiological outcome. Neurological deficits were documented in two patients, which declined during the course. There were no severe postoperative complications. The results of the present study demonstrate that the described surgical procedure in fractures of the fifth lumbar vertebra does not promote an anatomic restoration of the fractured vertebra, nor of the segmental lordosis. However, the clinical results do not correlate with the radiological outcome (Kaminski et al., 2002). Nonoperative treatment with early mobilisation without external support seems to be the treatment of choice (Andreychik, Alander, Senica, \& Stauffer, 1996).

Burst Fractures occur due to failure under the axial load of both the anterior and middle columns originating at the level of one or both end plates of the same vertebra. Cervical injury is an injury hip bones most often cause disability and death, from several studies there is a correlation between the level of cervical injury with morbidity and mortality, i.e. the higher the level of cervical injury the higher the morbidity and mortality (Stewart, 2002).

About $10 \%$ of patients with decreased consciousness who are sent to the Emergency Department as a result of a traffic accident always suffer cervical injury, both injury to the cervical bone, supporting tissue, and injury to the cervical spine. Traffic accidents and falls are the cause of most cervical bone fractures. Traumatic cervical subaxis (C3-7) is more common than cervical $\mathrm{C} 1$ and $\mathrm{C} 2$. Cervical trauma often occurs in patients with a history of motor vehicle accidents at high speed, trauma to the face and head, there is a neurological deficit, pain in the neck, and multiple trauma (Weishaupt, 2010).

\section{Generalized Anxiety Disorder}

American Psychiatric Association (2013) explained about Generalized Anxiety Disorder (GAD) affect many people. While that has been made in terms of therapy, in this case psychotherapy for GAD can be concluded if the effectiveness is still far from complete and there is still much to be learned about GAD (Arntz, 2003). Two features of the GAD symptoms stand out. First, GAD is characterized by what is called excessive behavior. Patients complain of frequent and difficult to control concerns, as did Andrews et al. Andrews, Hobbs, Borkovec, Beesdo, Craske, et al. (2010) recommend that the disorder be renamed "generalized anxiety disorder". Second, GAD is highly comorbid with depression (Kessler, Berglund, Dewit, Ustun, Wang et al., 2002).

Research on GAD focuses on predominant symptoms; worry. In some scientific clinical literature, these symptoms have been treated according to the hypothesis of "worry as anxiety" or "worry as avoidance behavior" (Dygdon and Dienes, 2014). For example two 
conceptualizations have influenced the learning theory of worry and therapy. The first conceptualization is based on classical conditioning and describes worry as synonymous with anxiety (O'Neill, 1985). Anxiety is understood as a conditioned response (CR) caused by an aversive conditioned stimulus (CS) (Cataria, 2013). Scientific interest in the "worry due to anxiety" hypothesis appears to have diminished and supports the second theory of learning hypothesis, discussed below; however, it may still be relevant in clinical practice. Individuals differ in the accuracy in using words to label personal events [8-11]. Some individuals, who complain of concern, may use the label to denote what professionals call anxiety. In such a case, the conceptualization of "worry as anxiety" is appropriate (Andrews et al., 2010).

\subsection{METHODOLOGY}

This study uses a single-case experimental design, namely a research design that aims to evaluate the effects of a treatment or single case intervention. The single case in question can be several clients in one single group or case in one client. This design is considered appropriate to do human-related research, especially when the measured behavior cannot be averaged (Latipun, 2008). This is a case study of qualitative in depth investigations of a single person with burst fracture frankle-c. The outcome assessment battery was designed to capture both interviewer and self-report assessment of anxiety, diagnostic status, other psychiatric symptoms (e.g., depression), interpersonal problems, and general functioning.

Structured Clinical Interview based on DSM IV-TR. The current investigation used the Structured Clinical Interview for the DSM-IV$\mathrm{R}$ to assess the Axis I diagnostic status of study Clients. It was conducted by trained independent evaluators and reviewed in a consensus case conference. A principal diagnosis of GAD was required for study entry. "Principal diagnosis" was operationally defined as the disorder associated with the most severe current impairment and/or distress, with the 0-8 distress/ impairment severity scale.

Interview methods are autoanamnesa and alloanamnesa. Autoanamnesa describe how the life story of Clients from childhood to adults. It provides an overview of the Client's disruption journey. Alloanamnesa describes the Client's life story based on the significant others.

\section{Respondents}

This case study explained about client with burst fracture at Orthopedic Hospital. The client is a 54 years old mother. The client had an accident, which was struck by a building wall in front of one of the hospitals in Karanganyar on Sunday, October 6, 2018. The client was trading satay at the client's shop in front of the hospital. The building is under construction, then the building wall collapses and hits the client's body. The client has bruises on the thighs and back, so the client can't walk.

The client was taken to Hospital by the client's husband and son. Since this incident the client has had nightmares and is often awake at night. The client also feels the client's heart beats faster. Every client is awake from his client's sleep as if seeing many people around him. Doctors at Hospital refer client to be taken to Orthopedic Hospital. The client is brought by the client's husband and son to the hospital, then the client gets treatment. When clients are treated at the Orthopedic Hospital, clients also experience nightmares. Nightmares that clients experience as there are many people around the client's bed, this makes the client often awake at night. This incident makes clients often worried, anxious, and feel nervous at night.

\section{Research Instruments}

Beck Anxiety Inventory (BAI). The BAI (Beck, Epstein, Brown, \& Steer, 1988) is a 21-item selfreport scale that assesses common features of anxiety, with a focus on cognitions, on a 4-point severity scale. It has been widely used in studies of psychosocial treatments for anxiety. The BAI shows high internal consistency (0.92) and testretest reliability over 1 week (0.75). It has been found to discriminate anxiety disorders from nonanxiety disorders (Beck et al., 1988). Anxiety level categories can be seen in Table 1 below.

Table 1 Anxiety level

\begin{tabular}{ll}
\hline Range & Categorization \\
\hline $0-7$ & Minimal Anxiety \\
\hline $8-15$ & Mild Anxiety \\
\hline $16-25$ & Moderate Anxiety \\
\hline $26-63$ & Severe Anxiety \\
\hline
\end{tabular}

Intervention Procedure

Based on the analysis of the psychological assessment and dynamics that have been done by the practitioner, the client will be given psychotherapy using a psychoanalysis approach. Psychoanalysis therapy focuses on the release of psychic energy that is bound in subconscious conflicts that are the result of suppression of unconscious impulses and anxiety and have a relationship with resistance and transference (Austad, 2010). Personality anxiety avoidance and repression behavior that is usually done by clients as an effort to reduce anxiety affects the client's ego condition at this time. This is one of the factors that causes clients to experience psychiatric problems.

The success of psychotherapy can be seen from the good supportive relationship that develops naturally between Clients and therapists. This is commonly referred to as "helping alliance". Freud (Christoph, Christoph, Palacio, Fichter, \& Rudick, 2015) revealed that helping alliance is allowed to bring into consciousness and the absence of rejection in a long time and as a path to the effectiveness of psycho-analysis as a method of intervention. Supportive relationships (supportive relationships) provide an important role in the working of therapeutic relationships. This relationship focuses on helping Clients strengthen competencies, self-esteem, and achieve goals. 
Supportive techniques are the basis of therapy so they can be supported by expressive techniques and interpretations of the Core Conflictual Relationship Theme/ CCRT (Christoph, Christoph, Palacio, Fichter, \& Rudick, 2015).

Luborsky (Grenyer \& Solowij, 2006) expresses expressive techniques in therapy focusing on understanding and helping Clients to change. There are four stages in carrying out expressive techniques, namely:

1. Listening

The ability to listen is the ability of the therapist to listen to everything the Client expresses, including unrelated things and observing what is released, what is said, and how the Client's attitude or behavior. Luborsky (Grenyer \& Solowij, 2006) divides three phases in listening based on the level of understanding, namely listening to know (open inquiring listening), listening to form hypotheses (listening to form hypotheses), and listening to check the accuracy of hypotheses that have been formed (listening to check the accuracy of formed hyphotheses).

This stage is an important element of supportive therapy. Listening emphasizes that ideas and drives cannot be thrown out of one's mind and can interfere with daily life to relieve this pressure, the client needs to be encouraged to share his thoughts with the therapist and feel free to express the pressure that is faced. The client is convinced that everyone experiences an idea or pressure that interferes with his life, so there is no need to feel hesitant to convey on the therapist because the therapist will understand without blame or judgment. The client will be trained to break a negative view of yourself. The fact that the client is accepted by the therapist, despite showing his weaknesses, will encourage him to think again about himself. The goal of this therapy is limited to restore self balance without changing behavior premorbid and his personality, so that the client is not forced to open what is not is desirable.

2. Understanding

Understanding is the ability to start seeing patterns between the main symptoms and the relationships between topics. Understanding requires time, patience, and care in formulating before responding to clients. This stage is done in a way which is more directive by showing how unreasonable thoughts and feelings are how unfair the client is in punishing him. The client was convinced that he was not being are in a bad condition and have no hope of getting better. Always there people who are aware and understand their situation, so that in this session the client is strengthened and entertained so as not to punish themselves.

3. Responding

Responding is a communication act that is carried out to the client on what has been understood after listening before. Short responses take precedence over long and complex explanations. The client is convinced that he has something that can be developed. The therapist's role is to forbid the client to restrain himself and invites to reject the assumptions and irrational habits that actually interfere with his life all this time. Concrete suggestions are made to help the client set goals, drive away worry, master various thoughts, increase self-confidence, mastery of self and face various unpleasant situations with an objective attitude.

\section{Listening again}

Interpretation or response can affect how the client understands. Therefore, it is necessary to do an evaluation related to how the client's feelings, thoughts and understanding of the therapist's response. The good response from clients to what is conveyed by the therapist is that it can touch the side relating to the problem. This is marked by a decrease in anxiety levels and clients get a better experience.

The Core Conflictual Relationship Theme (CCRT) method is a descriptive summary of the core relationships of the client's problems. CCRT is used as a guide in the expressive component of the intervention. The CCRT technique contains narrative analysis delivered by the Client (naratives told). There are three aspects in the narrative analysis delivered by Clients, namely the wishes of the Client (W), the response of others to the Client (RO), and the response of the self (RS) (Christoph, Christoph, Palacio, Fichter, and Rudick, 2015).

Based on the explanation above, the objectives of the intervention to be carried out to the client are as follows:

1. Help clients to be able to express emotions appropriately.

2. Strengthening a weak ego due to unpleasant experiences.

3. Assist clients in achieving more effective self-awareness and personal relationships in dealing with anxiety through more adaptive ways by reducing repression that is commonly done.

Supportive-expressive therapeutic intervention designs refer to designs developed by Christoph, Christoph, Palacio, Fichter, and Rudick (2015) with the title "Brief Supportive-Expressive Psychodynamic Therapy for Generalized Anxiety Disorder".

\subsection{RESULTS}

Based on expressive supportive therapy that has been done, it is known that the client can begin to reduce the repression and anxiety felt. In addition, the client is also better able to understand his condition and the problems being faced. The catharsis process that has happened so far makes the client able to express what he feels and thinks so as to make the client feel the perceived burden is reduced. Clients can begin to open up to family members at home and conduct simple chats when parents are at home to reduce the habit of repression that was previously done. 
Clients begin to increase interaction with neighbors and friends to drain the loneliness that is felt and get support. The habit of praying in congregation at the beginning of time also begins to try clients after returning home from the hospital to calm down. The client also realizes the importance of drug consumption and routine checks during the healing process. The client also plans to end and reduce interactions with the client's boyfriend so as not to make the client feel depressed again.

The client's family understand the problem the client is facing all this time. The client's family also realizes the importance of communication between family members at home to reduce the burden on the client. In addition, awareness of the importance of drug consumption and regular doctor checks must also be realized by the client's husband. This is for the client's physical recovery process. The client's husband also tries not to limit the wishes of the client as long as it does not harm the client's self and family.

Before the practitioner gives the Beck Anxiety Inventory, the client's anxiety is 20 (moderate anxiety), and after 15 (mild anxiety).

Follow up was done two weeks after the intervention was given. The results shown on Figure 1 that the client has an anxiety score of 11 (mild anxiety).

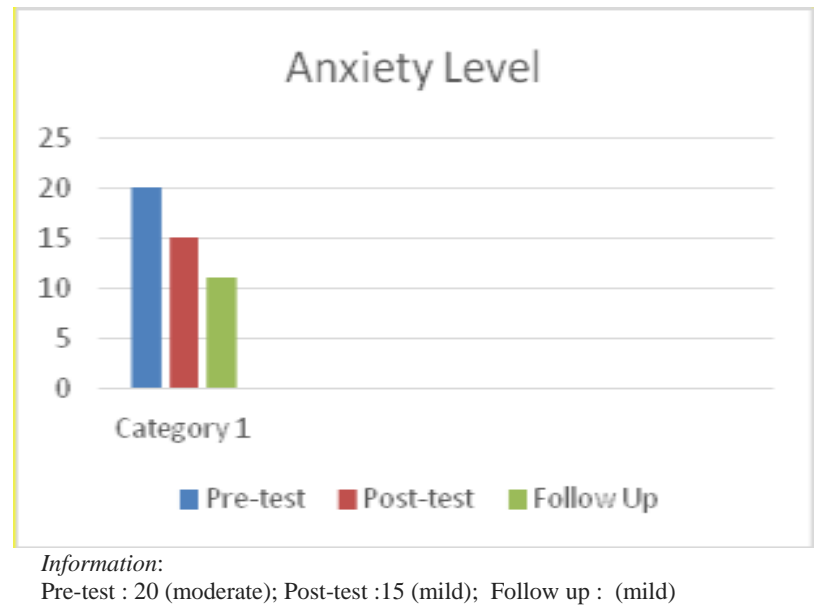

Figure 1 Difference score anxiety pre - post intervention and follow up

\subsection{DISCUSSION AND RECOMMENDATION}

First, dynamic therapy continues to be a widely practiced form of treatment in the community (Jensen, Bergin, Greaves, 1990), which suggests that many patients with GAD are commonly being treated with dynamic therapy. Developing and standardizing a particular dynamic therapy for GAD accomplishes the important first step of making it possible to evaluate the efficacy of dynamic therapy with this disorder.

The client is the fourth child of eight siblings. The client's father and mother are farmers in the tea garden. Since childhood, the client lived in Karanganyar with his parents and relatives. Weak family economic conditions make clients unable to go to school. From birth the client does not get ASI from the client's mother. This is because the client's mother is ill and cannot provide ASI clients.

Sigmund Freud (Feist \& Feist, 2009) divides the stages of child development in the infantile period into three phases based on primary erogenous zones which undergo the most important developments namely the oral, anal and pallid phases. The oral phase is the phase of development that takes place in the first year of an individual's life. While in this phase, the most important and sensitive erogenous area is the mouth, which is related to satisfying the basic needs for food or water. Stimulation or stimulation of the mouth such as sucking, for babies is a behavior that causes pleasure or satisfaction. Freud also believed that someone who did not complete the original stage well when an adult someone would be fixated on the oral stage.

This also relates to the theory of object relations which is part of Freud's theory (Feist \& Feist, 2009) concerning instinct theory. Freud also explained that father's power and control, object relations theory tend to be more maternal by emphasizing maternal intimacy and nurturing. In addition, Klein stresses the importance of the first four to six months after birth, which he considers to be the most critical period for personality development, where the child's relationship with the mother's breast is the basis of a subsequent relationship with another person.

Since the client was born, the client was taken care of by the client's siblings, because the client's mother was ill and could not take care of the client. Generally, a child from birth has attachment to the mother. Bowlby (Ainsworth, 1969) also explained that the importance of attachment in the first year of life of the baby and mother instinctively has a desire to form an attachment. Parenting that involves many people or alternates and is not settled by one or two parents causes instability that is felt by the child, both in terms of the size of love, attention, and sensitivity of response to the needs of children. Children will find it difficult to build a stable emotional attachment because the caregivers always change. This will affect the development of children and make it difficult for children to adjust because they tend to be anxious and lack of confidence.

The role of fathers who tend to be authoritarian towards the client, makes the client feel uncomfortable in living the client's life. The client's father is too protective of the client, so the client's father participates in arranging the client's match. The client experiences disappointment with the client's father for choosing the right partner for the client. This also affects all aspects of the client's life.

The client has performed cyst removal surgery and is causing the client to always worry about his health. This is also reinforced by the events where the people closest to the client died due to a very serious illness, this also makes the client worry about his health Anxiety arises in the client for fear that if the pain will return to attack the client. This is a traumatic event for the client.

Death of the people closest to them due to illness and accidents experienced by the client makes the client's worries increase. This becomes a precipitating event for clients. The death of the closest person due to the client's illness makes the client worry about the health 
of the client, husband, and client's children. Another thing that makes the client worried is the client's physical limitations after an accident makes the client afraid of not being able to help the client's husband in making a living. The client is also afraid of not being able to make the client's family happy and fail to be a parent to the client's children.

This client concern makes the client always suppress all the problems that clients experience. The client has difficulty expressing his feelings to those closest to him, especially family. The client feels that all problems experienced by the client are the responsibility of the client to solve it himself.

Freud (Alwisol, 2012 there are three things that happen after someone presses a traumatic event into the subconscious. First, in the subconscious the impulses and desires that are suppressed do not change. second, impulse and desire to enter the subconscious in a different form from the subconscious. This will create greater anxiety and is difficult to control by those who experience it. Third, the impulses and desires are suppressed expressed in other forms.

Uncontrolled self-defense mechanism causes the client to experience total anxiety characterized by difficulty concentrating, dry mouth, anxiety wherever the client is, excited almost every time, and worried about the state of self and the client's future.

\subsection{CONCLUSION}

Based on the results of this study, it can be concluded that there are differences is the generalized anxiety disorder of client with anxiety level from Beck Anxiety Disorder. The expressive supportive therapy that has been done, it is known that the client can begin to reduce the repression and anxiety felt. In addition, the client is also better able to understand his condition and the problems being faced. The catharsis process that has happened so far makes the client able to express what he feels and thinks so as to make the client feel the perceived burden is reduced. Clients can begin to open up to family members at home and conduct simple chats when parents are at home to reduce the habit of repression that was previously done.

Clients should maintain self-awareness to regularly consume drugs and not be lazy to carry out routine checks to the hospital. Making it a habit to communicate openly to the family can improve the quality of existing communication for the better. The client's willingness to communicate can reduce anxiety and gain support from the environment when faced with confusion or problems.

The family, especially the client's husband is able to provide a safe and comfortable atmosphere when at home. This can make the client feel comfortable to be open or tell the problem that is felt. The family also wishes to provide support and does not limit the client's wishes. The family continues to provide supervision, attention, and is actively involved in the client's healing process through drug consumption and routine hospital visits.

\section{References}

Andreychik, D.A., Alander D.H., Senica, K.M., Stauffer, E.S. (1996). Burst Fractures of The Second Through Fifth Lumbar Vertebrae. The Journal of Bone and Joint Surgery, 78, 1156- 1166

Alwisol. (2012). Personality of Psychology Revised Edition. Malang: UMM.

American Psychiatric Association. (2013). Diagnostic and Statistical Manual of Mental Disorders (5th ed.). Washington, DC.

Amodeo, M. (1995). The Therapist's Role in the Drinking Stage. In S. Brown (Ed.), Treating Alcoholism, 95-132. San Francisco: Jossey-Bass.

Andrews, G., Hobbs, M.J., Borkovec, T.D., Beesdo, K., Craske, M.G., et al. (2010). Generalized Worry Disorder: A Review of DSM-IV Generalized Anxiety Disorder and Options for DSM-V. Depress Anxiety 27, $134-147$.

Arntz, A. (2003). Cognitive Therapy Versus Applied Relaxation as Treatment of Generalized Anxiety Disorder. Behaviour Research and Therapy, $41,633-646$.

Austad, S. (2010). Recent Advances in Vertebrate Aging Research 2009. Aging Cell, 9(3), 297-303.

Beck, A.T., Epstein, N., Brown, G., Steer, R.A. (1988). An Inventory for Emeasuring Clinical Anxiety: Psychometric Properties. The Journal of Consulting and Clinical Psychology, 56(6), 893-897.

Beesdo, K., PhD., Knappe, S., Dipl-Psych., \& Pine, D. S, MD. (2009). Anxiety and Anxiety Disorders in Children And Adolscents: Develpomental Issues and Implications for DSM-V. Psychiatric Clinics of North America, 32(3), 483-524.

Bellak, L. (1958). Schizophrenia: A Review of the Syndrome. New York: Grune \&: Stratton.

Beres, D. (1956). Ego Deviation and the Concept of Schizophrenia. The Psychoanalytic Study of the Child, 11,164-235. New York: International Universities Press.

Brown, S. (Ed.). (1995). Treating Alcoholism. San Francisco: Jossey-Bass.

Cataria, A.C. (2013). Learning (5th ed.). Cornwall-on-Hudson: Sloan Publishing: New York.

Christoph, P. C. Ph.D., Christoph, K. C., Ph.D., Palacio, D.W., M.S.W., Fichter, M., Ph.D., \& Rudick, D., Ph.D. (2015). Brief Supportive-Expressive Psychodynamic

Therapy for Generalized Anxiety Disorder. Pennsylvania: Center for Psychotherapy Research Department of Psychiatry University of Pennsylvania.

Denis, F. (1983). The Three Column Spine and Its Significance in the Classification of Acute Thoracolumbar Spinal Injuries. National Library of Medicine, 8(8), 817831.

Dewald, P. A. (1971). Psychotherapy: A Dynamic Approach (2nd ed.). New York: Basic Books.

Dygdon, J.A., \& Dienes, K.A. (2014). Generalized Anxiety Disorder and Depression: A Learning Theory Connection. Journal of Depression and Anxiety, 3(1), 1- 6.

Feist, J., \& Feist, G.J. (2009). Theories of Personality. Boston: McGraw-Hill.

Frank, J. D. \& Frank, J. B. (1991). Persuasion and Healing (3rd ed.). Baltimore, MD: Johns Hopkins University Press.

Grenyer, B.F., \& Solowij, N. (2006). Supportive-expressive Psychotherapy for Cannabis Dependence. Australia: Faculty of Health and Behavioral Sciences-Papers University of Wollongong Australia.

Hackl, W., Hausberger, K., Sailer, R., Ulmer, H., \& Gassner, R. (2001). Prevalence of Cervical Spine Injuries in Patients with Facial Trauma. National Library of Medicine, 92(4), 370-376

Jensen, J.P., Bergin, A.E., \& Greaves, D.W. (1990). The Meaning of Eclecticism: New Survey and Analysis of Components. Professional Psychology: Research and Practice, 21, 124-130.

Kaminski, A., Muller, E.J., Muhr, G. (2002). Burst Fracture of the Fifth Lumbar Vertebra: Results of Posterior Internal Fixation and Transpedicular Bone Grafting. European Spine Journal, 11, 435 - 440.

Kessler, R.C., Berglund, P.A., Dewit, D.J., Ustun, T.B., Wang, P.S., et al. (2002). Distinguishing Generalized Anxiety Disorder from Major Depression: Prevalence and Impairment From Current Pure and Comorbid Disorders in the US and Ontario. The International Journal of Methods in Psychiatric Research, 11, 99111

Latipun. (2008). Psikologi Konseling. Malang: UMM Press

Luborsky, L.B. (1984). Principles of Psychoanalytic Psychotherapy: A Manual for Supportive Expressive (SE) Treatment. 
Ruscio, A.M, PhD., Hallion, L.S, Ph.D., \& Lim, C. C. W, MSc. (2017). Cross-sectional Comparison of the Epidemiology of DSM-5 Generalized Anxiety Disorder Across the Globe. JAMA Psychiatry, 74(5), 465-475.

Stewart, J.M. (2002). A Blended E-Learning Approach to Intercultural Training. Industrial and Commercial Training, 34(7), $269-271$.

Weishaupt, MA. (2010). Velocity-dependent Changes of Time, Force and Spatial Parameters in Warm Blood Horses Walking and Trotting on a Treadmill. Equine Veterinary Journal, 42(28). 530-537. 